\title{
Can 'Civil Enterprises' survive in the market? Some game theoretical considerations on the one-shot game
}

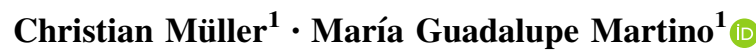

Received: 19 June 2019/Accepted: 6 April 2020/Published online: 17 April 2020

(C) The Author(s) 2020

\begin{abstract}
Civil enterprises (CEs) are firms whose main goal is to produce benefits for the community, working according to a logic of reciprocity. In this paper we discuss, from a game theoretical perspective, as to what extent it is possible for such enterprises to survive in competition with profit-maximizing firms in the marketplace, since market competition might take the form of a prisoner's dilemma game, where the public good at stake is the commitment to moral rules. In those games cooperative strategies are strictly dominated by the defective behavior of the players, i.e. CEs would not survive while retaining their values. We argue that market competition is more appropriately modelled as an n-firm model and show that, given a sufficient number of CEs in the market, they can survive despite having to interact with for-profit firms, even when the game is played only once.
\end{abstract}

Keywords Civil enterprises · n-person prisoner's dilemma $\cdot$ Reciprocity · Unconditional cooperation

\section{Introduction}

The Civil Economy approach, as developed by Italian economists Bruni and Zamagni (2007), intends to promote reciprocity relationships in economic activity as a way of humanizing the economy. Central to this conception is the notion of "Civil Enterprises" (henceforth CEs), referring to firms whose main goal is to

María Guadalupe Martino

mgmartino@yahoo.com.ar

Christian Müller

christian.mueller@wiwi.uni-muenster.de

1 Institute for Economic Education, University of Münster, Scharnhorststraße 100, 48151

Münster, Germany 
produce benefits for the community as a whole. CEs are characterized as economic organizations that are oriented to the common good and work according to the principle of reciprocity, which implies cooperative behavior, beyond the limits that a mere exchange of equivalents (market logic) would impose (Bruni and Zamagni 2007, p.181 ff.). However, according to the Civil Economy approach, the market is expected to be a plural place where different kinds of economic organizations coexist, including CEs and common for-profit firms (p. 185). That is, the authors consider that not all market participants will share CEs' moral commitment and reciprocal behavior. However, from a game theoretical perspective, moral behavior under market competition is usually considered to be subject to a prisoner's dilemma (PD) (McClennen 1999). In such games cooperative strategies are strictly dominated by the defective behavior of the players; thus, the only equilibrium is a situation of mutual defection as a stable, but Pareto-inferior result.

But how then could one expect Civil Enterprises to survive in such a setting? Is it possible for CEs, under those conditions, to compete with usual for-profit firms, maintaining their values? As a solution, one might consider repetitions of the underlying PD game. As is well known from game theory, in the PD supergame, an infinite number of cooperative equilibria is conceivable. Reciprocal behavior in a market competition PD, therefore, may be a successful equilibrium strategy. This solution, however, is explicitly ruled out. According to Bruni's and Zamagni's definition (2007, p.170), reciprocity cannot be categorized in terms of reputation in repeated games, because according to them, CEs are guided by intrinsic motivations, while reputation seeking would be a self-interested motivation. In this sense, the authors seem to have a non-consequentialist interpretation of reciprocity, since in their conception of "unconditional reciprocity", 1 such behavior does not depend on the other players' choices. In terms of the PD setting, such "unconditional reciprocity" is thus equivalent to "unconditional cooperation".

In this article, we, therefore, raise the question of whether such a reciprocal behavior can be a viable strategy in a non-iterated prisoner's dilemma game. Using some simple game-theoretical considerations, we argue that even when market competition takes the form of a one-shot prisoner's dilemma game, in which cooperating is a dominated strategy for any firm, cooperation is not necessarily harmful for CEs. Firms choosing unconditional reciprocity may thus survive under certain circumstances.

The article is organized as follows: In the next section we present the main characteristics of CEs; in Sect. 3 we analyze competition between CEs and forprofit enterprises in terms of the standard 2-person prisoner's dilemma; in Sect. 4, we extend our argument to n-firms competition between CEs and profit-oriented enterprises. In Sect. 5, we show under which conditions CEs can survive in the market, according to the results of the multi-party prisoner's dilemma game. We conclude with some comments and observations.

\footnotetext{
1 The concept will be more accurately defined in Sect. 2.
} 


\section{The concept of civil enterprise}

By means of their Civil Economy approach, Bruni and Zamagni attempt to revive a trend of thought of the same name, led by Antonio Genovesi in the eighteenth century, which considered the "market as a place centered around the principle of reciprocity and civil virtues" (Bruni and Zamagni 2007, p.13). The contemporary Civil Economy perspective stresses this idea and, in the authors' words, "sees human sociability and reciprocity as core elements of normal economic life. They are neither parallel to, nor prior to or subsequent to, normal economic life. Civil economy shows us that principles other than profit and instrumental exchange can find a place within the economic activity itself" (Bruni and Zamagni 2007, p.17).

Therefore, according to this perspective, reciprocity is to be introduced into the market through economic organizations that work according to this principle, i.e. "civil enterprises." This concept comprises a variety of organizations, e.g. social cooperatives or social enterprises (in the sense of Borzaga and Defourny 2001), ${ }^{2}$ "Economy of Communion" enterprises (Bruni 2014; Lubich 2003), ${ }^{3}$ and certain non-profit organizations, all of them sharing some central characteristics, i.e. they intend to contribute to the common good (Bruni and Zamagni 2007, p.181 ff.), they are multi-stakeholders organizations (in the sense of Freeman 1984) and, particularly, they behave according to the principle of reciprocity. Bruni and Smerilli (2015) also refer to the organizations of the civil economy as "value-based organizations," emphasizing the fact that their aim is not profit but an ideal motivation, which is somehow related to the intrinsic motivations of their promoters (p.33).

The notion of reciprocity, according to Bruni's and Zamagni's (2007, p.168) conception, presents three main characteristics, first, "unconditional-conditionality" (in the sense of Caillé 1998), i.e. "the services I render to the other are not a precondition for him/her to act, and yet I cannot reach my objective if the other does not respond." (Bruni and Zamagni 2007, p.167); second, the bi-directionality of the transfers, and finally their transitivity, meaning that the reciprocal response does not necessarily have to be directed to the person who prompted it, but possibly towards a third party. These features should differentiate this behavior from typical market relationships (i.e. exchange of equivalents), and also from genuine altruism, which Bruni and Zamagni (2007) nevertheless interpret as derivatives of reciprocity (p. 173). The "unconditionality" of the reciprocity principle, as defined by the authors,

\footnotetext{
2 Bruni and Zamagni (2007, p.183) admit that their notion of civil enterprises has much in common with the concept of social enterprises (as considered by Borzaga and Defourny (2001)), but prefer the denomination "civil enterprises" in order to differentiate them explicitly from traditional cooperatives, which are often identified with social enterprises.

3 The Economy of Communion project was created by the catholic Movement of the Focolare in Brazil in 1991, and today is extended to around 860 enterprises in different parts of the world Bruni (2014, p.38). Bruni (2008, p.528) defines it as "business which are managed with a new culture (the 'culture of giving') and put their profits into communion, with the aim of demonstrating a part of humanity "with no-one in need' and becoming a model for many". In other words, through the sharing of profits and an ethical and responsible system, they intend to participate in the common good (Frémeaux and Michelson 2017, p.705). In practice, they share their profits in three parts: one third is reinvested in the firm so as to develop and create new jobs; another third is assigned to the development of a new culture based within the communion; and the remaining third goes directly to the poor.
} 
implies that firms adopting it are assumed to behave cooperatively in every situation, i.e. independently of the other market participants' behavior, since they are guided by intrinsic motivations (pp. 190-191). ${ }^{4}$

\section{Standard wisdom: Self-harm through reciprocal behavior in competition as a PD}

According to Bruni and Zamagni, CEs should interact in the market with usual forprofit firms, and there should be freedom to choose between different types of economic institutions. In this sense, they maintain that "...variety [of enterprise types] within the market is the essential condition for the prosperity of the economic system" (Bruni and Zamagni 2007, p.185).

However, as mentioned before, market competition might take the form of a PD type game, where the public good at stake is the commitment to moral rules, since firms would have incentives to "some kind of cheating," leading to such a PD structure (Tullock 1985, p.1073). Thus, how can CEs survive when market competition takes this form? Assuming away all principal-agent relationships and collective decision-making processes within enterprises, such situation can be modelled as a game of two firms, 1 and 2. Firm 1 is under consideration here, and Firm 2 usually represents "all other firms" as a collective actor. Each firm can choose between two strategies: cooperation $(C)$ or defection $(D)$.

"Cooperation" in the sense of civil enterprises would mean for example, transmitting useful information (e.g. regarding vacancies or possible business partners), providing services by using inactive (or partly inactive) resources, starting or continuing an unprofitable labor relationship in favor of the employee, providing higher service quality than required (Crivelli and Gui 2014, p.40), ${ }^{5}$ being a fair competitor, protecting workers, and of course they should be expected to avoid any unethical practices. "Defection," on the other hand, could be to take advantage of those cooperative practices instead of reciprocating, or other kind of immoral behavior such as financial statement fraud, bribing contractors, manipulating exhaust gas data, or lying to make profits.

Thus, the dilemma confronting these two companies is as follows:

In Fig. 1, the first entry of the vector in each cell of the matrix, gives the payoff of Firm 1, the second entry, that of Firm 2. The function $f_{i}(v)$ describes firm i's payoff when it behaves as a CE; and $g_{i}(v)$ represents the payoff from acting as a for-profit firm. Each payoff will be a function of parameter $\mathrm{v}$, which indicates the number of other CEs in the market. A (two-person) prisoner's dilemma always exists, when the following payoff sequence holds for each of the two firms: $g_{i}(1)>f_{i}(1)>g_{i}(0)>f_{i}(0)$.

In terms of game theory, behaving as a $\mathrm{CE}$ would mean choosing the cooperative strategy in a prisoner's dilemma game. If both firms decided to choose the CEs' strategy (C, C), their situation would be Pareto-superior, compared to the one in which both were for-profit firms (D, D), and it would even be a Pareto optimum. But, the standard

\footnotetext{
${ }^{4}$ For other conceptions of reciprocity in business see Göbel et al. (2013).

5 The authors refer to Economy of Communion Enterprises.
} 
Firm 2 (all other firms):

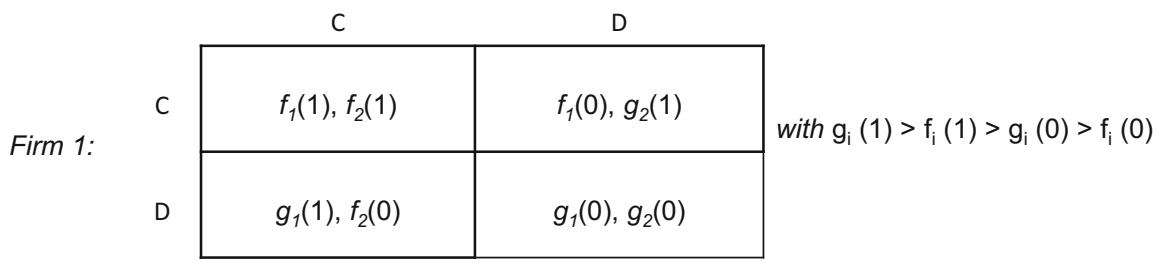

Fig. 1 Market competition as 2-firm prisoner's dilemma

result of this game will of course be that for both firms, to "defect" (D) is the dominant strategy, which leads them to the Nash equilibrium (D, D). This means, for a Firm i, it will always be more rewarding to be a for-profit firm than a CE. There are two-quite different-reasons for defection being the best strategy:

1. If the competitor does not cooperate, the company will defect out of a protection motive. Cooperating while the other player(s) choose defective strategies would mean risking getting into the position of a "sucker," the player with the lowest payoff $f_{i}(0)$. As Thomas Hobbes put it hundreds of years ago, cooperating unilaterally while all others are defecting "were to expose himself to prey" (Hobbes 1651, p.80).

2. However, if one or the other companies behave like CEs and cooperate, but firm $i$ defects unilaterally, this is from a free-riding motive-or simply out of greed. Company $i$ then simply wants to earn more than it would by behaving morally and would thus impose the costs of its own self-interest seeking on all other competitors. Immoral behavior here simply increases profits.

In the conception of the Civil Economy, CEs are supposed always to choose the cooperative strategy, that is, to ignore the strategic prisoner's dilemma structure, and to cooperate unconditionally, no matter what the others do. According to Bruni and Zamagni (2007, p.191), these firms' behavior would be guided by intrinsic motivations (in the sense of Deci and Ryan 1985 or, within an economic context, Frey 1997), which would lead them to cooperate anyway, immediately excluding the free-riding motive. It is to be noted that CEs do not choose to always cooperate because they obtain a higher payoff (as it would result after including in the payoff, for example, a psychological component for the satisfaction of behaving ethically or for having social preferences in the sense of Fehr and Fischbacher 2002). That is, the payoffs in our analysis do not reflect preferences, as they usually do in game theory, but just represent the incentive structure given by monetary payoffs. CE's choice in this context is to renounce a higher payoff in monetary terms for the sake of morality. ${ }^{6}$ The problem lies in the fact that

\footnotetext{
${ }^{6}$ Following Sen (1977), who considers the importance of "commitment" on behavior, which may be motivated by ethics but also by other cultural reasons (p. 334), Bruni (2008) maintains that intrinsic motivations should be differentiated from 'utility' or 'welfare' to which the concept of payoff is related. In this sense, according to the author, firms may follow a strategy of unconditional cooperation out of ethical motives, but the payoffs will depend of the consequences of their actions, which are the same for all players (p. 56). Thus, CEs present the same structure of payoffs as any firm but choose to renounce in order to follow an ethical standard.
} 
neglecting the protection motive would threaten their long-term survival in the market, so that, in order to survive, they would have to act as conventional for-profit firms, abandoning their original aim. Standard wisdom thus suggests that within competitive markets, there is no hope of CEs surviving: as long as morality is subject to a (one-shot) standard prisoner's dilemma game, each CE firm choosing unconditional cooperation would harm itself. As a consequence, profit-making firms would simply crowd CEs out of the marketplace.

As is well-known from game theory, this may only be different when the interaction of firms is repeated. Such game repetitions (infinite or unknown) can fundamentally alter the strategic characteristics of the underlying dilemma game. It is a "folk theorem" in game theory that, under these conditions, an infinite number of (non-) cooperative (subgame perfect) equilibria become possible, e.g. Tit-for-Tat strategies (Axelrod 1984). Such cooperative equilibria are possible, even under the conditions of an n-person prisoner's dilemma (for details Taylor 1987). According to these studies, cooperative behavior can be rational; it is then not only not selfdamaging but is even in the participants' own best self-interest. But this is not what Zamagni and Bruni seem to have in mind when they claim that "reciprocity in our sense can never be categorized in terms of a repeated game: It is a relationship, and so it cannot be confused with reputation, which is an intangible asset." (Bruni and Zamagni 2007, p.170).

\section{A more differentiated view: competition as a multi-firm dilemma}

If it is not the iteration of the game that makes a Civil Enterprise cooperate in a prisoner's dilemma game, under what conditions could this be conceivable? Can CEs even afford it to follow their values, or would they not be obliged to behave as profit maximizers in order to survive?

We think that for a civil enterprise it might well be possible to survive in the game of the market even when the underlying prisoner's dilemma game is played just once. In the following analysis, we argue that the representation of market competition as a two-person (firm) game where Player 1 represents the firm in question and Player 2 "all other firms," is reductionist. The implicit assumption of this kind of model is that each firm will reason: "As long as the others do not cooperate, I have to defect too, so as not to harm myself."

Market competition, however, is far more complex than that, because "all other firms" should not be considered as a monolithic block. If market competition is more appropriately modeled as an n-firm game (with $n \geq 2$ ), we obtain a more differentiated view. It can then be shown that CEs' survival in the market is not impossible when competition is represented as a one-shot prisoner's dilemma game, since, in a multi-firm dilemma, the protection motive of defection may work out in a completely different manner than in a two-firm game.

In order to demonstrate this, we will generalize the above two-firm dilemma to the case of "many" firms $i$ (with $i=1, \ldots, n$ ), using the existing variants of the nperson prisoner's dilemma $n \geq 2$ in the literature that differ from each other only in the details (Hardin 1971; Hamburger 1973; Hamburger 1979 ch.7; Schelling 1973; 
Szilagyi 2003; Taylor 1987, p.82). When the game is modelled for $\mathrm{n}$ firms, in order to maintain the central strategic features of the two-firm game, the following characteristics must be maintained:

- Choice set of two strategies: Each of the n firms can choose between just two alternatives: a CE's strategy $(C)$ or a profit maximization one $(D)$.

- Dominance of defection: $D$ (defection) is the dominant strategy for each of the $\mathrm{n}$ firms; that is, $g_{i}(v)>f_{i}(v)$ for all $i$, therefore $\left(D_{1}, D_{2}, \ldots D_{n}\right)$ is the only Nash equilibrium of the game.

- Pareto-superiority of universal cooperation: $\left(C_{1}, C_{2}, \ldots, C_{n}\right)$ must therefore be Pareto-superior compared to the Nash equilibrium $\left(D_{1}, D_{2}, \ldots, D_{n}\right)$. In terms of the payoffs:

$f_{i}(n-1)>g_{i}(0) f$ or all $i$.

The payoffs of any firm $i$ depend on two factors:

- the choice of its own strategy: CE's behavior $\left(C_{i}\right)$ or profit maximization $\left(D_{i}\right)$

- the total number $\mathrm{v}$ of CEs in the market.

The latter condition presupposes that the payoff does not depend on which of the other companies are CEs, but just on the total number of such firms.

The function $f_{i}(v)$ represents the payoff of firm $\mathrm{i}$, when $\mathrm{i}$ itself, and $\mathrm{v}$ additional firms choose to be a CE; $g_{i}(v)$, on the other hand, denotes firm $i$ 's payoff, when it itself chooses to be a for-profit firm, while v other companies are CEs. Since the presence of more CEs in the market reduces the exploitation possibilities for CEs and increases the benefits of unilateral defection for for-profit firms, we may say that both strategies for any firm are more rewarding the greater the number of other CEs (the larger $\mathrm{v}$ ). Therefore, it is assumed that $f_{i}(v)$ and $g_{i}(v)$ are both strictly monotonically increasing for all $0 \leq v \leq n-1$. This assumption will be decisive for the final result of the game. It should be noted that the payoff functions, $f_{i}(v)$ and $g_{i}(v)$, can differ for each individual firm i, as the prisoner's dilemma we consider does not need to be symmetrical with respect to the payoffs.

On the basis of these assumptions, we obtain the graph depicted in Fig. 2 (similar to Schelling 1973, p.388; Hamburger 1973, p.37 and 42; Hamburger 1979, p.159 ff.), in which the ordinate shows the payoff of firm $i$, and the abscissa represents the number $\mathrm{v}$ of other CEs, whereby the origin of the coordinate system is the situation of universal defection $\left(D_{1}, D_{2}, \ldots, D_{n}\right)$. In the following analysis, a vector with an index "- $i$ " represents firms with uniform behavior, thus, $\left(D_{i}, D_{-i}\right)$ will be the simplification of $\left(D_{1}, D_{2}, \ldots, D_{\mathrm{n}}\right) ;\left(C_{i}, D_{-i}\right)$ of $\left(D_{1}, D_{2}, \ldots D_{i-1}, C_{i}, D_{i+1}, \ldots, D_{n}\right)$, etc.

Because of the dominance condition $g_{i}(v)>f_{i}(v)$, for any $v$ curve $g_{i}(v)$ is always higher than $f_{i}(v)$, i.e. for-profit firms' payoffs are always greater than for CEs. Though the function neither needs to be linear nor parallel as, for the sake of simplification, as depicted in Fig. 2, they cannot intersect, given the condition of dominance. Since, in a PD, universal cooperation is by definition Pareto-superior to universal defection, payoffs in $\left(C_{i}, C_{-i}\right)$ are greater than in $\left(D_{i}, D_{-i}\right)$, that is, $f_{i}(n-1)>g_{i}(0)$.

It can easily be seen that the multi-firm PD, as defined here, contains the usual two-player prisoner's dilemma of Fig. 1 as a special case. For $n=2$ we obtain 


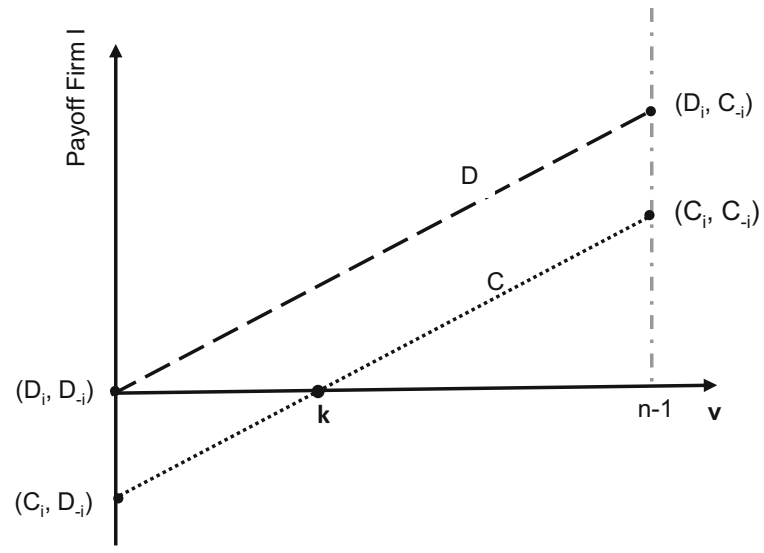

Fig. 2 Market competition as n-firm prisoner's dilemma

$g_{i}(1)>f_{i}(1)>g_{i}(0)>f_{i}(1)$, which corresponds to the usual payoff ratio of the twoplayer game.

As can be observed in the graph, parameter $k$, marking the intersection of the cooperating function $f_{i}(v)$ with the abscissa, indicates a situation in which the payoff of cooperating is the same as that of the Nash equilibrium of universal defection $\left(D_{1}, \mathrm{D}_{2}, \ldots, D_{n}\right)$.

\section{Conditions for civil enterprises to survive in a one-shot game}

The n-person model of the PD-type competitive situation reveals a central fact not representable in the two-firm constellation. In the multi-entrepreneur model, cooperation no longer has to be self-defeating in all circumstances, for in the multicompany situation, the protection motive of defection plays a completely different role than in the small group.

Our analysis implies firstly that there is a minimum number $\mathrm{k}$ of civil enterprises above which it is worthwhile to be a civil enterprise. Even if only some, though not all the other companies choose the cooperative strategy, by cooperating in the PD setting, Firm i can be made better-off than in the situation of universal defection. This means that, if there is a sufficient number of CEs operating in the market, it is possible for them to survive despite having to compete with for-profit firms.

Correspondingly, we will call parameter $\omega_{i}$ the reciprocation threshold:

$$
\omega_{i}=\frac{k}{n-1}
$$

$\omega_{i}$ denotes the minimum proportion of other CEs required in order for firm $i$ to survive as a $\mathrm{CE}$, i.e. to adopt a strategy of reciprocal behavior (understood as unconditional cooperation) without harming itself. 
From this expression, we derive a parameter $\mu_{i}$, which we may call the reciprocation leeway:

$$
\mu_{i}=1-\frac{k}{n-1} \text {. }
$$

It indicates the scope within which firm $i$ is able to act as a CE and compete with for-profit firms, without thereby harming itself. In other words, $\mu_{i}$ denotes the extent to which the protection motive plays no role for firm $i$. Since the company does not have to fear being pushed into the sucker's position by other firms, it can afford to behave as a CE. The only costs that the company would still have to face, are the opportunity costs derived from the lost benefits associated with the free-riding option. Assume (according to Laplace's principle of insufficient reason) that the other $n-1$ companies choose to cooperate with equal probability, because there is no evidence that any particular firm will be more likely to behave like a CE than another one. The reciprocation leeway $\mu_{i}$ can then be interpreted as a nonexploitation probability, i.e. the probability of not being damaged by competing with for-profit enterprises or, in other words, of not being imposed to "external costs" (Buchanan and Tullock 1962) by non-cooperating third parties.

\subsection{The minimum number of CEs}

Given our definition of the leeway of reciprocation $\left(\mu_{i}\right)$, its extent will depend on the market size, as well as on the minimum number of competing CEs required in order for a $\mathrm{CE}$ to survive in the market $(k)$. Let us consider the values of the reciprocation leeway for a given market size (n), by varying $\mathrm{k}$ between its extreme values, that is, 0 and $n-1$.

When $k=0$, the leeway of reciprocation is $\mu_{i}=1$, and the probability of exploitation is zero, which means that the protection motive of defection does not matter at all. In this case, a CE would be able to coexist with for-profit firms, even as the only one of that type in the market.

At the other extreme, when $k=n-1$, for firm $i, \mu_{i}=0$. This means that the presence of just one for-profit firm competing in the market, would make it impossible for firm $\mathrm{i}$ to survive as a CE; for in this case, the probability of exploitation is maximal, as the firm depends completely on other companies' behavior and the protection motive of defection is always significant.

Thus, the entire leeway of reciprocation $\mu_{i}$ for a given market size $\mathrm{n}$ is given between those two extreme cases, namely, $\mu_{i}=1$, where a CE can survive in the market, even being the only one of its kind and $\mu_{i}=0$, where $\mathrm{CE}$ survival requires all other firms also to be CEs.

\subsection{The role of market size $(n)$}

We now turn to the question of how the reciprocation leeway changes, when the market size $(n)$ varies, given the minimum number $k$ of other CEs required.

If, for a given $\mathrm{k}$, the total number of enterprises in the market grows, $\mu_{i}$ approaches the value of one. The scope of reciprocation increases, as the 
reciprocation threshold decreases. Therefore, a smaller proportion of CEs to the total number of firms is required in order for them to survive in market competition, that is, to obtain at least the Nash equilibrium payoff.

If, conversely, for a given $\mathrm{k}, \mathrm{n}$ tends towards the other extreme case of $k=n-1$, the reciprocation threshold increases and the leeway of reciprocation $\left(\mu_{i}\right)$ decreases accordingly to zero. This would be the special case of the ordinary two-player prisoner's dilemma, with $n=2$ and $k=1$, so that for firm $i, \mu i=0$. No CE would therefore have a chance of surviving in market competition. This may well be the reason for the high emphasis on the protection motive, although in more realistic n-firm constellations that are intended to be analyzed that way, this need not apply at all.

\section{The price of reciprocity}

In their conception of the Civil Economy, Bruni and Zamagni (2007) describe civil enterprises as firms acting on a moral principle of reciprocity. In this article, we, therefore, raised the question as to how CEs are able to survive when morality is a public good that is subject to a prisoner's dilemma game.

The prisoner's dilemma describes a conflict between "the rational" and the "reasonable" (see Sibley 1953 on this distinction), e.g. between the dominance principle from game theory and the issue of public wealth. As is well known, the dilemma results in a stable, but Pareto-inferior Nash equilibrium. The reason for the dilemma is that the players have no incentive to behave morally. In this type of situation, no one can rely on the others to cooperate, so that each will defect. Since firms will often find themselves in similar situations in the marketplace with the same competitors again and again, it may be reasonable to model at least certain types of competition as prisoner's dilemma supergames. But this would not correspond with Bruni and Zamagni's claim that a CE's reciprocal behavior is intrinsically motivated and cannot be modelled as self-interested cooperation in a repeated game (Bruni and Zamagni 2007, p.170).

This article shows that it may nevertheless be possible for CEs to survive even when market competition is a one-shot game, i.e. when the game is played only once (or repeated finitely often). As the foregoing considerations demonstrate, the opinion which is usually found in the field of business ethics, that under conditions of market competition there is (practically) no room for the pursuit of individual morality (e.g. Homann and Blome-Drees 1992), which would imply that there is no room for CEs, is, at least in this universality, wrong. The two-person prisoner's dilemma model, on which this assertion is generally based, is not suitable for illustrating multi-firm competition conditions. We, therefore, extend the analysis to an n-firm dilemma (with $n \geq 2$ ), in order to conceive intermediate solutions.

The good news from our analysis is that even in the one-shot case where cooperation is the dominated strategy for any firm, it is possible for CEs to survive in market competition with for-profit firms under certain conditions. Assuming that the presence of CEs in the marketplace increases the payoffs of all kinds of firms (CEs and for-profit firms), we show that, given a sufficient number of competitors 
that are CEs, behaving as a civil enterprise need not to be self-defeating. If Firm $i$ is a $\mathrm{CE}$, it may obtain a higher payoff than in the situation where all firms are forprofit, i.e. in the Nash equilibrium $\left(D_{1}, D_{2}, \ldots, \mathrm{D}_{\mathrm{n}}\right)$ of the $n$-firm game. Choosing reciprocal strategies here pays off in the sense that a cooperator at least receives the payoff of the equilibrium situation of mutual defection. ${ }^{7}$ This, however, does not mean that it is "economically rational" to behave like a civil enterprise. On the contrary, even if the leeway of reciprocation is positive $\left(\mu_{i}>0\right)$, abiding by the norm of reciprocity $(C)$ remains "irrational" in this sense. To cooperate is still not in the firms' own best self-interest for $C$ remains a dominated strategy. Otherwise, the underlying game situation would not be a prisoner's dilemma. To state that reciprocal behavior may pay-off means something different here; if a sufficient number of other firms are also civil enterprises, company $i$, if it chooses to be a CE as well, suffers no disadvantage from the Nash equilibrium of mutual defection. However, in social dilemma situations, civil enterprises may bear the opportunity costs of not choosing to free ride. The conflict between profit-seeking and morality may then remain unsolved. At the end of the day in the Civil Economy, it is no different from life in general; morality has its price. But, in the words of Bruni (2009, p.130) "...if, in order to avoid the (individual and collective) risks of unconditionality, in modern societies the third form of reciprocity [unconditional] were to be eliminated, I am convinced that civil life would be much poorer, and ultimately implode" (our translation). It may be this price that makes life worth living.

Open Access This article is licensed under a Creative Commons Attribution 4.0 International License, which permits use, sharing, adaptation, distribution and reproduction in any medium or format, as long as you give appropriate credit to the original author(s) and the source, provide a link to the Creative Commons licence, and indicate if changes were made. The images or other third party material in this article are included in the article's Creative Commons licence, unless indicated otherwise in a credit line to the material. If material is not included in the article's Creative Commons licence and your intended use is not permitted by statutory regulation or exceeds the permitted use, you will need to obtain permission directly from the copyright holder. To view a copy of this licence, visit http:// creativecommons.org/licenses/by/4.0\%.

\section{References}

Axelrod, Robert. 1984. The evolution of cooperation. New York: Basic Books Inc., Publishers.

Borzaga, Carlo, and Jacques Defourny (eds.). 2001. The emergence of social enterprise. London: Routledge.

Bruni, Luigino. 2008. The Economy of Communion. In Pursuing the common good: How solidarity and subsidiarity can work together. Proceedings of the 14th Plenary Session, 2-6 May 2008, Casina Pio

\footnotetext{
7 Schelling (1973) uses the term "coalition" to refer to the group of players that choose the dominated strategy. Such "coalition" somehow induces the members to act in a certain way, "disciplining individual choices of its members or making a collective decision on behalf of them" (p. 394). As examples of coalitions in this sense, the author considers a union or trade association, a veterans' organization, or ad hoc coalitions such as people who sign up for a blood bank. In this sense, projects such as Economy of Communion (see footnote 5) or B-Corps (https://bcorporation.net/) could be examples of coalitions of CEs which would allow those firms to survive in market competition, providing them an environment of cooperation which strengthens CEs' confidence in their own behavior and values, and reduces the probability of being exploited.
} 
IV, eds. Margaret S. Archer and Pierpaolo Donati, 527-534.Vatican City: Pontifical Academy of Social Sciences.

Bruni, Luigino. 2009. El precio de la gratuidad. In El precio de la gratuidad: nuevos horizontes en la práctica económica, ed. Luigino Bruni and Cristina Calvo, 15-172. Buenos Aires: Ciudad Nueva.

Bruni, Luigino. 2014. The Economy of Communion. A project for a sustainable and happy economic future. Journal of Dialogue \& Culture 3 (2): 32-41.

Bruni, Luigino, and Alessandra Smerilli. 2015. The economics of values-based organizations: An introduction. London, New York: Routledge.

Bruni, Luigino, and Stefano Zamagni. 2007. Civil economy: Efficiency, equity, public happiness. Bern: Peter Lang.

Buchanan, James M., and Gordon Tullock. 1962. The calculus of consent logical foundations of constitutional democracy. Ann Arbor: University of Michigan Press.

Caillé, Alain. 1998. Il terzo paradigma: Antropologia filosofica del dono. Torino: Bollati Borlinghieri.

Crivelli, Luca, and Benedetto Gui. 2014. Do 'Economy of Communion' Enterprises Deserve the 'Social' Label? A Comparative Discussion of their Aims and Logic of Action. Revista Portuguesa de Filosofia 70 (1): 28-43.

Deci, Edward L., and Richard M. Ryan. 1985. Intrinsic motivation and self-determination in human behavior. New York: Plenum.

Fehr, Ernst, and Urs Fischbacher. 2002. Why Social Preferences Matter-The Impact of Non-Selfish Motives on Competition. Cooperation and Incentives. The Economic Journal 112 (478): C1-C33.

Freeman, Edward R. 1984. Strategic management: A stakeholder approach. Boston, Mass.: Pitman.

Frémeaux, Sandrine, and Grant Michelson. 2017. The Common Good of the Firm and Humanistic Management: Conscious Capitalism and Economy of Communion. Journal of Business Ethics 145 (4): 701-709. https://doi.org/10.1007/s10551-016-3118-6.

Frey, Bruno S. 1997. Not just for the money: An economic theory of personal motivation. Cheltenham: Edward Elgar.

Göbel, Markus, Rick Vogel, and Christiana Weber. 2013. Management Research on Reciprocity. A Review of the Literature. Business Research 6 (1): 34-53. https://doi.org/10.1007/BF03342741.

Hamburger, Henry. 1973. N-person Prisoner's Dilemma. The Journal of Mathematical Sociology, 3 (1): 27-48. https://doi.org/10.1080/0022250X.1973.9989822

Hamburger, Henry. 1979. Games as models of social phenomena. San Francisco: W. H. Freeman.

Hardin, Russell. 1971. Collective action as an agreeable n-prisoners' dilemma. Behavioral Science 16 (5): 472-481. https://doi.org/10.1002/bs.3830160507.

Hobbes, Thomas. 1651. Leviathan or the Matter, Forme, \& Power of a Common-wealth Ecclesiasticall and Civill, Prepared for the McMaster University Archive of the History of Economic Thought by Rod Hay. London.

Homann, Karl, and Franz Blome-Drees. 1992. Wirtschafts- und Unternehmensethik. Göttingen: Vandenhoeck \& Ruprecht.

Lubich, Chiara. 2003. Economía de Comunión: Historia y profecía. Buenos Aires: Ciudad Nueva.

McClennen, Edward F. 1999. Moral Rules as Public Goods. Business Ethics Quarterly 9 (1): 103-126.

Schelling, Thomas C. 1973. Hockey Helmets, Concealed Weapons, and Daylight Saving: A Study of Binary Choices with Externalities. The Journal of Conflict Resolution 17 (3): 381-428.

Sen, Amartya K. 1977. Rational Fools: A Critique of the Behavioral Foundations of Economic Theory. Philosophy \& Public Affairs 6 (4): 317-344.

Sibley, W.M. 1953. The Rational Versus the Reasonable. The Philosophical Review 62 (4): 554. https:// doi.org/10.2307/2182461.

Szilagyi, Miklos N. 2003. An Investigation of N-person Prisoners' Dilemmas. Complex Systems 14 (2): $155-174$.

Taylor, Michael. 1987. The possibility of cooperation, [Rev. ed]. Cambridge: Cambridge University Press.

Tullock, Gordon. 1985. Adam Smith and the Prisoners' Dilemma. The Quarterly Journal of Economics 100: 1073-1081.

Publisher's Note Springer Nature remains neutral with regard to jurisdictional claims in published maps and institutional affiliations. 